\title{
КОГНИТИВНЫЕ НАРУШЕНИЯ И ДЕМЕНЦИЯ КАК ОСЛОЖНЕНИЕ ЦЕРЕБРОВАСКУЛЯРНОЙ НЕДОСТАТОЧНОСТИ В ПЕРИОД ИШЕМИЧЕСКОГО ИНСУЛЬТА
}

\section{COGNITIVE DISORDERS AND DEMENTIA AS A COMPLICATION OF CEREBROVASCULAR INSUFFICIENCY DURING THE PERIOD OF ISCHEMIC STROKE}

A. Dzhibilov

I. Khamgokova

L. Tlapshokova

Summary. The key risk factors for cerebrovascular diseases are arterial hypertension (AH), atherosclerosis and diabetes mellitus; genetic factors are also important, in particular, the polymorphism of the APOE and MTHFR genes. At the stage of the formation of non-neurological factors, processes are already taking place that determine how pronounced and how quickly the cerebrovascular pathology will develop, how pronounced and significantly the structures of the brain will be damaged and this or that clinical symptomatology will form. At the stage when the diagnosis of cerebrovascular pathology cannot yet be established, prerequisites are already being created for the brain cells to be negatively affected.

The results of these studies indicate that the presence of vascular risk factors in young and middle age is a potential cause of cognitive decline in adulthood. Those who, at the age of 40-44, had a higher total score for risk factors, demonstrate the worst results in tests that assess memory, information processing speed, and verbal ability.

In arteriopathy, vascular patency is impaired, blood flow decreases, focal or diffuse lesions develop, which leads to the formation of a certain neurological deficit. Simultaneously with these additional negative processes, the development of inflammatory changes, a violation of the permeability of the blood-brain barrier, and secondary autoimmune lesions occur. In general, this leads to the fact that brain cells are affected, regardless of whether they are in the zone of strategic damage to the vascular system or not.

In acute disorders of cerebral circulation, neuronal damage occurs not only in the area of acute cerebral ischemia, but also in non-ischemic areas of the brain that have synaptic connections with the primary lesion focus (in the hippocampus, thalamus, substantia nigra). In the ischemichypoxic cascade, heterogeneous etiological agents trigger the same type of processes that cause disruption of cell functioning and its death.

Today we are talking about the close relationship of vascular pathology and neurodegenerative processes. With vascular pathology,
Джибилов Аслан Юрьевич

Врач невролог, психиатр-нарколог, ГБУз «ММБ» 2. Нарткала; Аспирант, Кабардино-Балкарский государственный университет г. Нальчик aslan.dzhibilov@mail.ru

Хамгокова Инна Ураловна

Врач невролог, Городская поликлиника № 1 2. Нальчик Prepodavatel00@mail.ru

Тлапшокова Лариса Беталовна

Д.м.н., профессор, врач невролог, ГБУз

«Республиканская клиническая больница» г. Нальчик Prepodavatel00@mail.ru

Аннотация. Ключевыми факторами риска цереброваскулярных заболеваний является артериальная гипертензия (АГ), атеросклероз и сахарный диабет, важными также являются генетические факторы, в частности полиморфизм генов APOE и MTHFR. На этапе формирования неневрологических факторов уже происходят процессы, которые определяют то, насколько выражена и как быстро будет развиваться цереброваскулярная патология, насколько выражено и значимо будут повреждаться структуры головного мозга и формироваться та или иная клиническая симптоматика. На этапе, когда еще не может быть установлен диагноз цереброваскулярной патологии, уже создаются предпосылки для того, что клетки головного мозга будут находиться под негативным воздействием.

Результаты проведенных исследований свидетельствуют, что наличие сосудистых факторов риска в молодом и среднем возрасте являются потенциальной причиной когнитивного снижения в зрелом возрасте. Те, у кого в возрасте 40-44 года общая сумма по факторам риска была выше, демонстрируют худшие результаты в тестах, по которым оценивают память, скорость обработки информации, вербальные способности.

При артериопатии нарушается проходимость сосудов, уменьшается объем кровотока, развивающееся фокальное или диффузное поражение, которое приводит к формированию определенного неврологического дефицита. Одновременно с этими дополнительными негативными процессами происходит развитие воспалительных изменений, нарушение проницаемости гематоэнцефалического барьера, вторичные аутоиммунные поражения. В целом это приводит к тому, что клетки мозга поражаются, независимо от того, находятся они в зоне стратегического поражения сосудистой системы или нет.

При острых нарушениях мозгового кровообращения, нейрональное повреждения возникает не только в области острой церебральной ишемии, но и в неишемизированных участках головного мозга, которые имеют синаптические связи с первичным очагом поражения (в гиппокампе, таламусе, черной субстанции). При ишемически-гипоксическом каскаде неодно- 
neurodegenerative disorders occur in $30-80 \%$ of cases, and vice versa, with neurodegenerative processes up to $50 \%$ of the existing phenomena of vascular damage. Therefore, this combination must also be taken into account.

The clinical manifestations of cerebrovascular pathology are motor and cognitive impairments, emotional and behavioral disorders, speech impairment. It should be noted that vascular cognitive impairment is usually characterized by decreased attention, executive function and psychomotor retardation, while memory impairment may not be observed.

Keywords: cognitive impairment, ischemic stroke, failure, dementia. родные этиологические агенты запускают однотипные процессы, которые вызывают нарушение функционирования клетки и ее гибель.

На сегодня речь идет о тесной связь сосудистой патологии и нейродегенеративных процессов. При сосудистой патологии в 30-80\% случаев возникают нейродегенеративные нарушения, и наоборот, при нейродегенеративных процессах до 50\% имеющиеся явления сосудистого поражения. Поэтому такое сочетание тоже обязательно следует учитывать.

Клиническими проявлениями цереброваскулярной патологии являются двигательные и когнитивные нарушения, эмоциональные и поведенческие расстройства, нарушение речи. Следует отметить, что сосудистые когнитивные нарушения обычно характеризуются снижением внимания, исполнительных функций и психомоторной заторможенностью, в то время как нарушения памяти может не наблюдаться.

Ключевые слова: когнитивные нарушение, ишемический инсульт, недостаточность, деменция. егодня постинсультная деменция занимает лидирующее место в структуре инвалидизирующих состояний, а вместе с показателями заболеваемости цереброваскулярной патологии растет медико-социальная актуальность этой проблемы во всем мире. Эпидемиологические данные по распространенности постинсультной деменции различаются в зависимости от места проведения исследований и диагностических критериев, которые в них применялись [2, с. 18].

После первого года, частота новых случаев деменции линейно возрастает на $3 \%$ ежегодно (по данным госпитальных исследований) и на 1,7\% (по данным популяционных исследований). Результаты исследования с самым длинным сроком наблюдения продемонстрировали, что в течение 25 лет после инсульта деменция развивалась почти у половины пациентов [1]. Согласно сведениям других исследователей, перенесенный мозговой инсульт повышает риск развития деменции в 4-12 раз [6, с. 2875]. Синдром нарушения когнитивных функций в результате органического поражения мозга развивается у $25-30 \%$ лиц, подвергшихся инсульту, что приводит как к существенному повышению затрат на их уход, так и к увеличению смертности среди указанной когорты в 2-3 раза [2, с. 65].

По данным [5, с. 93], к числу наиболее значимых факторов риска развития постинсультной деменции относятся немодифицированные условия, такие как пожилой и старческий возраст; мужской пол; некоторые расово-этнические характеристики (известно, что люди желтой расы более склонны к постинсультной деменции). Несмотря на это (по результатам психиатрического интервью, субъективного и объективного анамнезов, нейро - и патопсихологической диагностики), существенной составляющей формирования деменции остается также низкий уровень образования пациента и наличие когнитивных нарушений в доинсультный период $[7$, c. 23].

Кроме того, выделяют ряд генетически обусловленных сосудистых заболеваний головного мозга (по результатам лабораторных исследований, анализов и т.д.), при которых также значительно повышается риск развития постинсультной деменции [3]. Впрочем, прогнозирование вероятности развития постинсультной 
деменции и ее тяжести напрямую зависят от характеристик церебральной катастрофы, а именно от количества и объема очагов поражения тканей мозга. Существенное значение в развитии когнитивных нарушений заключается в наличии церебральной атрофии, особенно в медиальных отделах височных долей и диффузных изменений белого вещества полушарий мозга (лейкоареозы).

Патоморфология сосудистой деменции - достаточно сложный процесс, ведь нередко клинические данные и патоморфологические исследования не дают возможности четко разграничить: где болезнь Альцгеймера, а где сосудистая деменция, поскольку симптомы этих заболеваний не только частично пересекаются, но и взаимно усиливают друг друга.

В частности, имеющиеся факторы риска приводят к нарушению гемореологических свойств крови и церебральной гемодинамики, которые, в свою очередь, могут вызвать острое нарушение мозгового кровообращения. Структурные изменения серого и белого вещества нервной ткани, ее гипоперфузия (микроинфаркты) становятся патоморфологическим субстратом феномена корково-подкорковой диссоциации и нарушения нейротрансмиссии в центральной нервной системе (ЦНС) [9, с. 2667].

Холинергическая система мозга участвует в обеспечении деятельности важных функций памяти (кора головного мозга, гиппокамп), регуляции сложных двигательных реакций, в частности механизма инициации движений, двигательных стереотипов (базальные ганглии), составлении циркадных ритмов и внимания (ретикулярная формация ствола мозга, холинергические структуры переднего мозга). Влияние холинергической системы на развитие когнитивных расстройств установленный в 1982 году, подтвержден результатами многочисленных исследований, которые свидетельствуют о снижении холинергических базально-кортикальных проекций мозга; значительную потерю холинергических нейронов в базальном ядре Мейнерта; сокращенную активность холинацетилтрансферазы, необходимой для синтеза ацетилхолина; снижение концентрации мускариновых и никотиновых рецепторов; наличие корреляций между редуцированной холинтрансферазой, потерю нейронов в базальных ганглиях и бляшках, содержащих $\beta$-амилоидный белок, между холинергическим дефицитом и снижением выполнения когнитивных тестов [10, с. 25].

Независимо от преобладания первичного нейродегенеративного процесса или сосудистого поражения головного мозга общим звеном патогенеза при развитии деменции является дефицит ацетилхолина в структурах, которые отвечают за когнитивные функции. Вследствие ишемии головного мозга возникает энергетический дефицит с последующими событиями, которые включают воспаление, глутамат-опосредованную эксайтотоксичность, чрезмерное накопление кальция, инициирование процессов, приводящих к гибели клеток, развитию окислительного стресса и структурно-функциональных изменений [8]. Посредники этих событий взаимодействуют друг с другом и способствуют повреждению клеток. Указанные процессы приводят к холинергическому дефициту и, в конце концов, вызывают когнитивные расстройства или деменцию.

\section{Эффективность холина а^ьфосшерат}

Холина альфосцерат является средством, которое относится к группе центральных холиномиметиков с преобладающим влиянием на ЦНС. Как носитель холина и предыдущий агент фосфатидилхолина, он потенциально может предотвращать и корректировать биохимические повреждения, которые имеют особое значение среди патогенных факторов психоорганического инволюционного синдрома, то есть может оказывать влияние на снижение холинергического тонуса и изменения фосфолипидного состава оболочек нервных клеток [6, c. 2877].

В течение последних десятилетий клиническая эффективность холина альфосцерата продемонстрирована в ряде исследований $[9$, с. 2669; 10, с. 45; 11, с. 209; 12, с. 920]. В открытом многоцентровом исследовании, проведенном в 176 неврологических центрах Италии с участием 2058 пациентов, лечение начиналось не позднее 10 дней после инсульта или транзиторной ишемической атаки [13, с. 1185]. Препарат назначали в дозе 1000 мг внутримышечно ежедневно в течение 28 дней с последующим пероральным приемом 1200 мг в сутки.

По данным диффузионной магнитно-резонансной томографии установлено, что уменьшение объема дефекта мозговой ткани при лечении холина альфосцератом достигается в течение месяца. Так, после курса терапии наблюдалось восстановление неврологического дефицита и способности больных к самообслуживанию. А в течение 6 месяцев, у более 2000 пациентов не было выявлено побочных гемодинамических эффектов, таких как влияние на сердечный ритм, артериальное давление. Результаты исследования продемонстрировали эффективность холина альфосцерата в компенсации неврологического дефицита, который является следствием цереброваскулярных нарушений.

Ученые [15, с. 77] провели клиническое исследование, в котором приняли участие 2484 пациенты после инсульта. На фоне терапии холина альфосцератом на- 
блюдалось достоверное улучшение когнитивных функций (памяти, внимания) и эмоционального фона по сравнению со стандартной терапией и плацебо, а также наблюдалась положительная динамика поведенческих расстройств и повышение повседневной активности. Данные исследования [11, с. 207] показали, что применение холина альфосцерата способствовало значительному улучшению когнитивных функций у пациентов с легким и среднетяжелым течением болезни Альцгеймера.

Итак, холина альфосцерат улучшает передачу нервных импульсов в холинергических нейронах; оказывает положительное влияние на пластичность нейрональных мембран и функцию рецепторов. Усиливая метаболические процессы в головном мозге, указанный препарат улучшает церебральный кровоток, активирует структуры ретикулярной формации головного мозга и восстанавливает сознание при травматическом его повреждении.

Лечение и профилактика цереброваскулярной патологии включает коррекцию сосудистых факторов риска (контроль артериального давления (АД), стабилизация ритма сердца, нормализация уровня глюкозы и липопротеидов в крови и т.д.), обеспечение здорового образа жизни (контроль массы тела, отказ от курения, ограничение употребления поваренной соли и т.д.), улучшение церебральной гемодинамики, нейропротекцию (цитопротекцию).

Учитывая сложность патофизиологического каскада при ишемическом инсульте и хронических нарушениях мозгового кровообращения, одной из перспективных терапевтических стратегий является выбор препарата с мультимодальным действием, который нацелен на ряд ключевых механизмов ишемического каскада.

Таким препаратом полифакторного нейропротекторного и метаболического действия, является депротеинизированный гемодериват из крови телят [10, с. 76]. Показано, что это средство повышает выживаемость клеток головного мозга и снижает их смертность в результате глобальной церебральной ишемии, улучшает когнитивные функции и общее клиническое состояние у пациентов с мультиинфарктной и смешанной деменцией, скорость когнитивных реакций, концентрацию внимания, мышление, социальную активность, а также восстанавливает нарушенные, вследствие ишемического инсульта, когнитивные функции. Результаты исследования [10, с. 87] продемонстрировали тенденцию к снижению частоты развития постинсультной деменции на $30 \%$ по сравнению с плацебо.

Для того чтобы установить диагноз нейрокогнитивного расстройства, необходимо провести оцен- ку восприятия, внимания, обучения и памяти, речи; управляющих, психомоторных и социально-когнитивных функций. О наличии у пациента малых нейрокогнитивных расстройств свидетельствует подтвержденное легкое (умеренное) снижение когнитивных функций по сравнению с прошлым уровнем в одной или нескольких когнитивных сферах на основе жалоб пациента или его родственников, нейропсихологических тестов, при этом когнитивное нарушение не вызывает нарушений независимости в повседневной активности. При наличии большого нейрокогнитивного расстройства человек нуждается в посторонней помощи.

Говоря о принципах лечения нейрокогнитивных нарушений, следует обратить внимание на то, что лечение обязательно должно включать устранение обратимых когнитивных расстройств (терапия метаболических нарушений, депрессии), коррекция факторов риска сердечно-сосудистых заболеваний (терапия АГ, кардиальной патологии), влияние на нейротрансмиттерные системы, применение нейропротекторов [9, с. 2672]. При терапии малых нейрокогнитивных нарушений, рекомендованы средства с метаболическим и вазоактивным действием, при больших нейрокогнитивных нарушениях - средства, действующие на нейромедиаторные системы. Обязательными являются немедикаментозные методы - повышение когнитивного резерва (когнитивные тренинги, развитие социальных связей, снижение уровня депрессии, выполнение умственных и физических упражнений), аромотерапия, музыкотерапия, психотерапия, массаж, психообразование пациента и его семьи, организация повседневной активности и тому подобное.

\section{Когнитивные нарушения: по $\triangle$ Хо $\Delta$ К л лечению}

Причинами сосудистых когнитивных нарушений могут быть атеросклероз, артериосклероз, амилоидная ангиопатия, васкулит, сосудистые аномалии и прочее. При прогрессирующей подкорковой энцефалопатии, кроме когнитивных нарушений подкоркового типа, у больных могут отмечаться нарушения походки/равновесия, мочеиспускания, эмоционально-мотивационные расстройства. Без этих дополнительных клинических проявлений устанавливать диагноз сосудистых когнитивных расстройств нецелесообразно.

Для сосудистых когнитивных расстройств не характерны нарушения памяти на текущие события, у пациентов с этой патологией не нарушаются запоминание и воспроизведение событий, в то же время возможна психомоторная заторможенность, трудности сосредоточения, нарушение произвольного внимания, аналитиче- 
ских способностей, снижение инициативы и мотивации, зрительно-пространственные нарушения.

Следует помнить, что при сосудистых когнитивных нарушениях довольно часто диагностируют не только атеросклероз, но и амилоидную ангиопатию, а потому применение тромболитической, антикоагулянтной и антитромбоцитарной терапии может способствовать возникновению геморрагических очагов, особенно при сосудистой подкорковой энцефалопатии. По сосудистой деменции показано, что применение антитромбоцитарной терапии замедляло когнитивное снижение, вызывало риск геморрагии [2, с. 81]. Считается, что при выборе антитромбоцитарной терапии предпочтение следует отдавать цилостазолу, который является альтернативой ацетилсалициловой кислоте. Терапия антитромбоцитарными препаратами должна использоваться только для вторичной профилактики инфарктов и инсультов. Статины не показали положительного влияния на профилактику деменции. Также нет убедительных доказательств влияния любых средств терапии сахарного диабета для предотвращения когнитивному снижению и деменции.

На сегодня не вызывает сомнения тот факт, что для сосудистой деменции и болезни Альцгеймера существуют общие факторы риска - сахарный диабет, повышенное АД, курение, болезни сердца, гомоцистеинемия, ожирения. Доказано, что АГ является фактором риска сосудистой деменции: тяжесть цереброваскулярных заболеваний ассоциирована с повышением систолического АД; прогрессирующее поражение белого вещества ассоциировалось с временными колебаниями АД. АГ в среднем возрасте должна строго контролироваться для профилактики когнитивных нарушений, поскольку она может приводить к ремоделированию сосудистой стенки, эндотелиальной дисфункции, развитию атеросклероза и как следствие тех изменений, которые вызывают развитие сосудистых когнитивных нарушений.
В то же время агрессивное снижение АД у пациентов старших возрастных групп связано с прогрессирующим развитием когнитивных нарушений и сосудистой деменции, а также риском присоединения альцгеймеровских изменений в мозге.

АГ, ожирение и гиперлипидемия теряют свое значение с возрастом, тогда как потенциально угрожающими становятся ортостатическая гипотензия, уменьшение массы тела, низкий уровень холестерина, ассоциированный с нарушениями катаболизма. Следует помнить, что факторами риска развития сосудистой деменции в среднем (45-65 лет) возрасте является АГ, ожирение, снижение слуха, в старшем (старше 65 лет) - курение, депрессия, ортостатическая гипотензия, физическая неактивность, социальная изоляция, сахарный диабет.

При сосудистых когнитивных нарушениях необходимо избегать применения витамина Е и антипсихотиков. Как симптоматическая терапия рекомендованы ингибиторы холинэстеразы (галантамин, донепезил), а также антагонисты NMDA-рецепторов (мемантин) [8]. При назначении ингибиторов холинэстеразы необходимо помнить, что они улучшают когнитивные функции у пациентов с болезнью Альцгеймера и деменцией с тельцами Леви, но существенно не влияют на сосудистую деменцию [8]. Кроме того, они могут вызвать снижение симпатических реакций и брадиаритмию, повышая риск ортостатической гипотензии и синкопе, поэтому назначаться они должны обязательно только после тщательного обследования пациента и проведения ортостатических проб. У пациентов со смешанной деменцией и ортостатической гипотензией к ингибиторам холинэстеразы целесообразно добавлять доноры холина, в частности холина альфосцерат, которые предопределяют нейропротекторное действие. Что касается терапии именно сосудистой деменции, то до сих пор не существует одобренных препаратов для лечения пациентов с этой патологией.

\section{ЛИТЕРАТУРА}

1. American Psychiatric Association. Diagnostic and Statistical Manual of Mental Disorders. 5th ed. Arlington, VA: American Psychiatric Publishing; 2013.Crossref

2. Bour A., Rasquin S., Boreas A., et al. How predictive is the MMSE for cognitive performance after stroke? J Neurol 2010;257:630-7.

3. Brainin M., Teuschl Y. The stroke patient and cognition.Hachinski V. In: Treatable and Potentially Preventable Dementias. New York, NY: Cambridge University Press; 2018.

4. Gutiérrez Pérez C., Savborg M., Pahlman U., et al. High frequency of cognitive dysfunction before stroke among older people. Int J Geriatr Psychiatry 2011;26:622-9.

5. Madureira S., Guerreiro M., Ferro J. M. Dementia and cognitive impairment three months after stroke. Eur J Neurol 2001;8:621-7.

6. Matz K., Teuschl Y., Firlinger B., Dachenhausen A., KeindI M., Seyfang L., et al.; ASPIS Study Group. Multidomain lifestyle interventions for the prevention of cognitive decline after ischemic stroke: randomized trial.Stroke. 2015; 46:2874-2880. doi: 10.1161/STROKEAHA.115.009992

7. Pendlebury S. T., Cuthbertson F. C., Welch S. J., et al. Underestimation of cognitive impairment by Mini-Mental State Examination versus the Montreal Cognitive Assessment in patients with transient ischemic attack and stroke: a population-based study. Stroke 2010;41:1290-3.

8. Philp I., Brainin M., Walker M. F., Ward A. B., Gillard P., Shields A. L., et al.; Global Stroke Community Advisory Panel. Development of a poststroke checklist to standardize follow-up care for stroke survivors.J Stroke Cerebrovasc Dis. 2013; 22: e173-e180. doi: 10.1016/j.jstrokecerebrovasdis.2012.10.016 
9. Puy L., Barbay M., Roussel M., Canaple S., Lamy C., Arnoux A., et al. Neuroimaging determinants of poststroke cognitive performance: the GRECogVASC study.Stroke. 2018; 49:2666-2673. doi: 10.1161/STROKEAHA.118.021981

10. Rist P. M., Chalmers J., Arima H., et al. Baseline cognitive function, recurrent stroke, and risk of dementia in patients with stroke. Stroke 2013;44:1790-5.

11. Sachdev P., Kalaria R., O'Brien J., Skoog I., Alladi S., Black S. E., et al.; International Society for Vascular Behavioral and Cognitive Disorders. Diagnostic criteria for vascular cognitive disorders: a VASCOG statement.Alzheimer Dis Assoc Disord. 2014; 28:206-218. doi: 10.1097/WAD.0000000000000034

12. Shi L., Zhao L., Yeung F. K., Wong S. Y., Chan RKT, Tse MF, et al. Mapping the contribution and strategic distribution patterns of neuroimaging features of small vessel disease in poststroke cognitive impairment.J Neurol Neurosurg Psychiatry. 2018; 89:918-926. doi: 10.1136/jnnp-2017-317817

13. TeuschlY., Ihle-Hansen H., Matz K., Dachenhausen A., Ratajczak P., Tuomilehto J., et al.; ASPIS Study Group. Multidomain intervention for the prevention of cognitive decline after stroke: a pooled patient-level data analysis. Eur J Neurol. 2018; 25:1182-1188. doi: 10.1111/ene.13684

14. Zhao L., Biesbroek J. M., Shi L., Liu W., Kuijf H. J., Chu W. W., et al. Strategic infarct location for post-stroke cognitive impairment: a multivariate lesion-symptom mapping study.J Cereb Blood Flow Metab. 2018; 38:1299-1311. doi: 10.1177/0271678X17728162

15. Zhou D. H., Wang J. Y., Li J., et al. Study on frequency and predictors of dementia after ischemic stroke: the Chongqing stroke study. J Neurol 2004;251:421-7.

( ) Джибилов Аслан Юрьевич ( aslan.dzhibilov@mail.ru ),

Хамгокова Инна Ураловна ( Prepodavatel00@mail.ru ), Тлапшокова Лариса Беталовна (Prepodavatel00@mail.ru ).

Журнал «Современная наука: актуальные проблемы теории и практики»

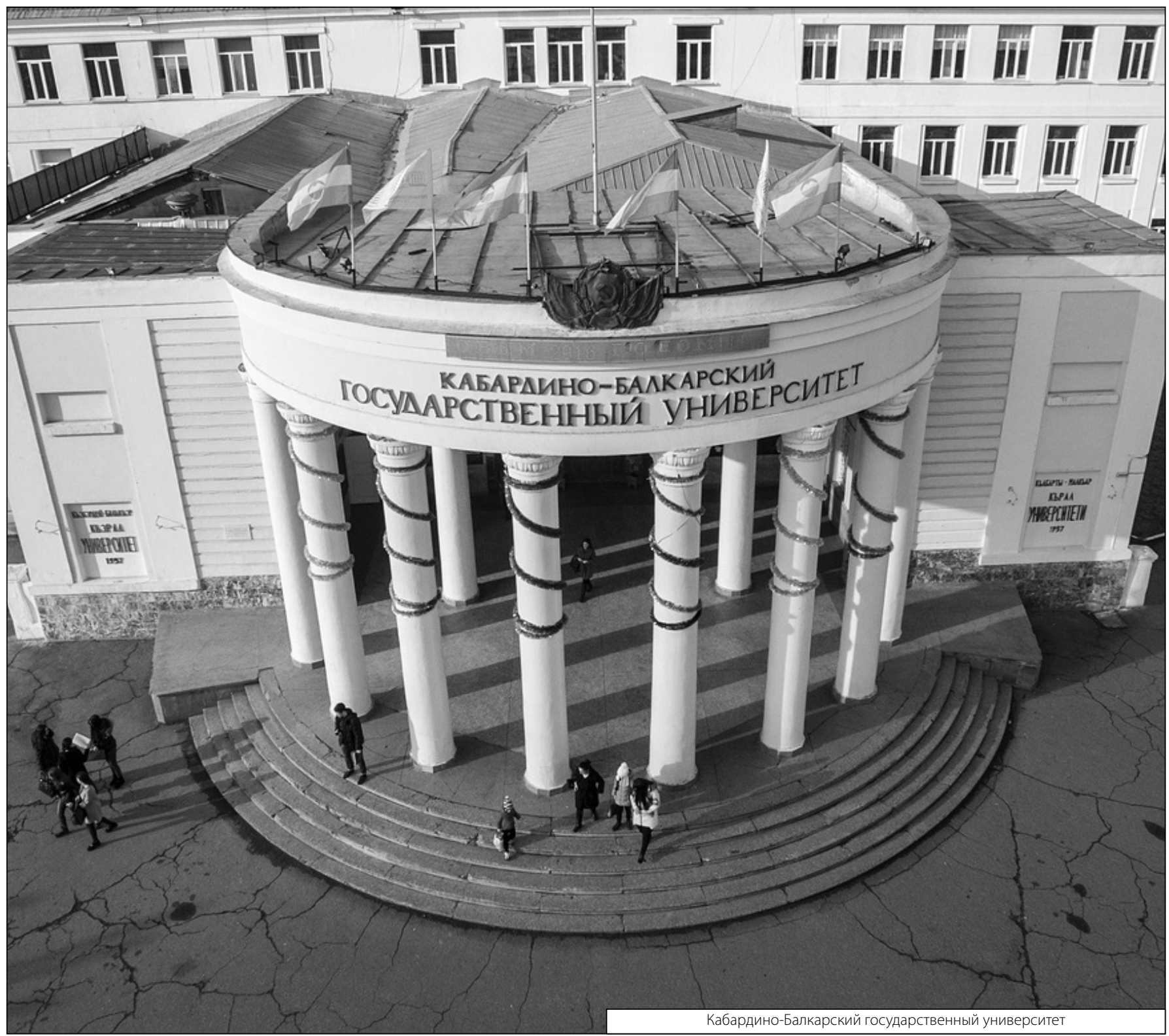

